\title{
Making and Breaking Space: Rethinking Montage in Digital Writing
}

\author{
Will Luers \\ Washington State University, Vancouver
}

\begin{abstract}
What is a montage theory and practice for the post-digital age? The modernist technique of montagethe creation of composite wholes from fragments-is at the heart of much of digital writing. In tweets, blogs, hypertext, multimedia fiction and recombinant poetry, the juxtapositions and constellations of distinct elements (text, image and sound) are the norm. Cinematic montage is usually opposed to Hollywood continuity or "invisible" editing, because in the latter the cut is masked. There is no gap to ponder, no room for the viewer. In popular movies, comics and commercials, montage has become normalized into a more fragmented continuity. Making space, more cohesive narrative worlds, through montage proved to be a faster method for conveying story and capturing attention. Digital expression has inherited both tendencies of montage: the making and breaking of space, but the dilemma for digital writers and artists is that the montage effects have been weakened by their ubiquity.
\end{abstract}

If montage is the foundation of all digital expression, how can its affective powers still be used as a counterpractice to the more homogenizing montage of corporate media? What is the role of montage when there are no dominant narrative flows to disrupt? This paper will look to both cinema artists and authors of digital fiction whose approaches to montage offer possible ways out of this montage dilemma. Rethinking montage in digital writing means pursuing new methods to make and break spaces through bifurcation, juxtaposition, multiplicity, and indeterminate processes. Drawing on the montage theories of Eisenstein, Benjamin, and Kluge, I explore works of digital fiction that favor fragmentation over immersion as a way toward a cognitively expansive narrative unity.

\section{Introduction}

Vernacular digital writing is a semiotic space full of intervals. Montage is ubiquitous. The digitization of media is itself a montage process, a fragmentation into distinct units that assemble numerically into wholes or effortlessly disassemble, glitch and decompose into parts. Breaking physical and/or conceptual space through montage introduces intervals, openings for the imagination to make a new whole. Montage aesthetics are evident in electronic literature and video games, in web design, digital marketing and social media. Digital interfaces are simultaneous montages of the networked, representational, symbolic, indexical, abstract, sequential and the collaged. Early blogging and video blogging communities had fostered a new type of "montage writing" that Walter Benjamin theorized about and practiced in his own time-an audiovisual, communal and political writing that samples from the heterogenous flows of experience. But with social media platforms, something has changed in digital writing. A kind of "continuity" is practiced in the auto-curated streams of photos and commentary on social media platforms. The interfaces and algorithms of platforms craft sanitized user-universes 
made of studied interests and behavior patterns. Constellations of distinct elements do make up the interfaces of Facebook, Twitter and YouTube, but the intervals between images, texts and videos are squeezed, smoothed out and made uniform. There are no authored spaces between Tweets or Facebook posts. No pauses or silences between the graduation picture and the obituary. Rhythm is uniform and regulated. Delivery is an endless conveyer belt. Social media has done wonders for discovery, connectivity and promotion, but the platforms have contributed little to the montage writing that Benjamin practiced and envisioned. We experience contemporary montage as an algorithmically curated flow in which semiotic spaces compete for constant attention. Loud assertions take precedence over silent intervals. Dislocated and drained, we retreat, detox and seek alternative diversions, but we are already aware of the shrinking intervals in semiotic life.

In a practical sense, montage is just a composition process that breaks unities into pieces in order to reconstitute new virtual unities - a destructive process that paradoxically aims for a wholeness made of potential space. Often used interchangeably with collage and assemblage, there is in the term montage a greater emphasis on a constructed whole. Derived from the French "monter" (to set up or stage), this "whole" does not necessarily mean narrative closure or structural hierarchy, although it can. Continuity editing in cinema is a type of montage in that fragments are assembled seamlessly into an apparent spatiotemporal whole by tricks of the eye. A point-of-view shot, for example, stitches together two discrete shots (someone looking at something) into a perceptual unity for the viewer. The more discontinuous editing associated with montage arts calls attention to the cut and the interval. Dislocation, processual change, ambiguity, opacity, disjunction, noise, temporal fragmentation can also give rise to new affective unities. Rapid montage, for example, might represent an agitated state of mind. Soviet Montage theory sought in discontinuous editing a new dialectical language to express Marxist ideas to an illiterate population. French and German montage of the 1920s used discontinuity to express dream states and silent interior "monologues."

If cinematic montage is active in many forms of vernacular and creative digital writing, how can its affective powers still be used as a counter-practice to the homogenizing montage of corporate digital platforms? What is the role of montage aesthetics when there are no dominant narrative flows to disrupt? Cinema artists in the silent era discovered the power of the interval, or, rather, they applied language techniques to a new art form. Making and breaking space is what we do with language - we digress, summarize, list, leave out, interrupt each other and ourselves. When writing breaks syntax or takes leaps in time and space in a way that is unconventional, we become aware of its effect and try to resolve the gap. An accomplished fiction writer will manage these gaps so that the reader is engaged with a portion of the text that isn't there. Selected details of subjects, setting, events and concepts, arranged with enough syntax and sequential logic, provide the material for immersion in a story world. The deliberate breaking of spatial continuities destroys this immersion, but asserts in its place new potential unities that might require some greater cognitive involvement.

Digital writing draws not only on cinematic montage, but also on a long history of literary montage. Stripped of the cinema theories that helped define it as modernist practice, montage has always been an expressive tool in language arts. Eisenstein and Griffith drew inspiration from 19th century literature for their editing innovations. The fragmented styles of Joyce, Woolf, Eliot and Pound were influenced by classical literary parataxis as well as by cinema. What cinema editing did for modernist, postmodern and conceptual literature was simply open up greater freedom in the conventions of literary parataxis. The poetic fragmentation of language allows for a dance around signification, for metaphor, for short-cuts and abstractions, delays and digressions in conveying meaning. Rethinking montage in digital writing means acknowledging this heritage of literary parataxis as well as of cinema 
montage in the evolution of digital texts, from hypertext to mobile app design. However, digital technologies add new ways of making and breaking space, namely through bifurcating links, multimodal and spatial juxtaposition, generative multiplicity and recombinant processes.

\section{Montage Theory and the Digital}

Much of digital fiction challenges normative reading practices in methods of making and breaking spaces. In the linear flow of a novel or film, intervals work to build a coherent narrative virtuality. A digital text often does not have such coherence or closure, because the relationships between media elements make up what Katherine Hayles calls a "cognitive assemblage":

.... particular kind of network, characterized by the circulation of information, interpretations, and meanings by human and technical cognizers who drop in and out of the network in shifting configurations that enable interpretations and meanings to emerge, circulate, interact and disseminate throughout the network. (Hayles, n.p.)

In the broken spaces of a digital fiction the whole is put into question or rather deferred to the cognitive experience of the reader. Hayles defines cognition as "the process of interpreting information in contexts that connect it with meaning." Digital authors, without the security of a controlled linear sequence that comes to an end, draw on other techniques for the reader's efforts at cognitive coherence. Repetition, variation and multiplicity are just some of these techniques. Although some early theorists of hypertext sought parallels with cinematic montage, the practice of montage in digital writing is more associated with modernist fragmentary writing or literary montage than with cinema arts. As digital texts incorporated more types of media, particularly in Flash works, a cinematic montage aesthetics emerges in digital fiction only to be overtaken by streaming HD video and immersive 3D spaces in video games and, of course, the end of Flash as a multimedia writing platform. Ideas of cinema montage are, however, latent in the practice of vernacular web writing with posts that combine short text with images and videos.

Soviet Montage theories begin with the Kuleshov effect. Lev Kuleshov's simple formulation that the interval between two shots could result in an idea not contained in either shot alone, had already been developed in practice in early Hollywood, particularly in the continuity editing of DW Griffith. But the idea of the interval had never been articulated as a method for constructing films. Students of Kuleshov-Sergei Eisenstein, Dziga Vertov and Vsevolod Pudovkin-went on to develop sophisticated new theories and practices. Pudovkin's montage was based on the "linkage" between shots and shares more qualities with Hollywood's "invisible" editing style where the interval is masked. Eisenstein and Vertov developed their own practice on the potential of the interval in montage, which in turn stimulated avant-garde artists and writers in the 1920's to make a new kind of cinema, a cinema that was more fragmentary and open for viewer interpretation. It is this modernist period of innovation with media and technology, before sync-sound in movies, that has perhaps had the most impact on the digital fiction today. In the collage and cinema art of the Dadaists, Surrealists and Futurists, breaking space was destructive of narrative immersion and constructive of new types of subjective unities.

Eisenstein's theory of cinema montage sought a dialectical synthesis in the contrast or collision not just of shots, but also in the juxtapositions of image, sound and text. His later organic conception of montage sought a "unity and inseparability of the whole and all its parts" (Arsenjuk, 180). Luka Arsenjuk describes Eisenstein's organic unity as a form in which, 
This method of ceaseless division, working toward ever widening potential unities without apparent closure, put Eisenstein into confrontation with Stalinist authorities who wanted narrative closure and political certainty in their propaganda. Dziga Vertov, whose very different montage methods were also too open-ended and ambiguous for Stalin, developed a theory of the interval that stitched disparate "unscripted" fragments into wide contexts of social and material life. Vertov's montage has perhaps had the greatest influence on digital artists and writers because his was a method of sample and remix. Eisenstein, with a background in theater, was still interested in model-building. Vertov's improvisational "kino-eye" was a machine-assisted signification process that opened human perception to non-human processes and effects. Writers of digital fiction do not write scripts first and then shoot and edit them. Digital tools are employed directly in the composition and the work grows out of a process of juxtaposing elements and applying machine effects. While contemporary digital montage is most inspired by Vertov, Eisenstein's evolved theories are useful for thinking of montage as a more deliberate method of composition with digital tools.

\section{Towards a Theory Digital Montage}

Eisenstein formulated five types of montage (72-83) that are still taught to students of time-based media and remain valuable heuristics for the temporal relations of fragments in digital texts.

- Metric Montage: cuts repeated at specific number of frames

- Rhythmic Montage: cuts according to movements in the frame

- Tonal Montage: metaphorical relationships

- Overtonal/Associational Montage: combining all of the above

- Intellectual Montage: non-representational ideas in shot relations

However, digital media that is organized and presented in computer systems with nonlinear access and interactivity, engenders new montage types. To add to Eisenstein's types, we might name four other digital montage types:

- Link Montage: gaps between nodes, scenes or episodes; bifurcations/forking paths; association of ideas

- Montage of Modalities: asynchronous image, text, sound, movement, haptic interaction design, graphic design, mapping

- Spatial Montage: coexistent spaces, simultaneity, parallelism (Lev Manovich)

- Recombinant and Computational Montage: variable/playable montage, semi-random processes for juxtaposition, polyvalent, fractal

While some of these proposed types might seem obvious or have already been theorized in other contexts, it will be useful to rethink these practices in consideration of how digital media is organized today, particularly on social media platforms. The Instagram user might apply metric and spatial montage to a post and a Tweeter might think up a clever montage association on a hyperlink or with an image. These common digital techniques are based on a consideration of the interval between elements. In many works of electronic literature these same montage methods are applied simultaneously. Pry by Gorman and Cannizzaro is a rich digital cinematic fiction that 
engages all five of Eisenstein's montage types as well as these new digital types. However, it is worth examining the distinct methods of making and breaking digital narrative spaces to perhaps uncover new composition possibilities for inventive fiction-making.

One of the exciting and frustrating aspects in many works of digital fiction is the lack of closure, not only a lack of clear endings, but also the missing information between fragments outside of linear development in works that involve recursion, or that recombine elements without end. Shelly Jackson's Patchwork Girl and My Body use the metaphor of stitching together texts to make a body - something broken, made whole again. Her graphic maps of this brokenness are also navigation maps. In the early days of hypertext, George Landow, Mark Bernstein, Adrian Miles and Clara Mancini (and many others) associated the hyperlink with a cinematic cut. Cinematic montage was a way to think about what happens between a user's anticipation of a link based on the context of the current node (what Miles describes as an "anxiety") and the authored destination. While there are plenty of examples of poetic association in the hyperlink, the challenge of hypertext fiction is always to maintain some narrative structure for a reader to follow. Links tend to signal to the reader where they go. Some works of hypertext fiction offer the reader a map of the linked nodes to help with orientation and with the cognitive efforts at meaningmaking. Hypertext and link-based digital fictions (in Twine for example) appear to be like cinema in this making and breaking of physical and/or conceptual spaces. A link may indicate a spatial or temporal jump or just a narrative association or digression.

In a more recent work of hypertext, With Those We Love Alive by Porpentine, an initial spatial continuity gives way to a broken dreamscape. Twine, the platform on which it is made, allows for programmed links, links that change the text of "passages" (in Twine terminology) based on certain criteria or variables activated in other links. The game-narrative incorporates features of spatial navigation from more traditional forms of Interactive Fiction, but does away with the navigational inputs in favor of the hyperlink. As the user explores the strange world, fragmented texts begin to make a virtual space. The links to passages at first appear static, but they begin to change dynamically with new details, new story information and new tasks for the user. Here is where link montage is activated to bring about the user-character's increasing engagement with the story world. By continuing to explore the same links in the search for information (and for escape routes), the user's every choice is implicated in the growing threat posed by the empress and her followers. What starts as a somewhat stable spatial relationship between passages, proliferates into a phantasmagoric montage of broken imagery where the intervals suggest a world that is not what it seems. Unlike more traditional immersive video games, montage and the emphasis on the interval engages the imagination in ways that put the viewer inside a virtual space rather than outside a represented space.

In The Language of New Media, Lev Manovich famously states that digital media, by being discrete elements in a database, no longer needs narrative as a formal container and can instead be organized for navigation based on the user's own interests and associations (227-228). Without this temporal ordering into sequence, montage seems to lose its aesthetic power. Making space through continuity editing is, according to Manovich, a construct that is no longer necessary now that digital media has been liberated from narrative sequence. He also associates cinematic montage more with breaking space and the creation of "visual stylistic, semantic, and emotion dissonance"(144). This dissonance he contrasts with the spatial montage from digital compositing which blends elements into a seamless, simultaneous whole. In Manovich's theorizing of spatial montage there is the beginning of a montage theory for digital media, but by excluding narrative in favor of database navigation and digital compositing, "where boundaries are erased rather than foregrounded," Manovich cuts off further discussions of 
virtual wholes (narrative or not) that are made of the intervals between media elements. Discussing Olia Lialina's My Boyfriend Came Back from the War, he emphasizes the works simultaneous juxtapositions and database organization, but not the gaps between text and image fragments and how these all form a virtual narrativity (Luers).

Spatial montage and multi-modal montage are the most common techniques in digital fiction. Each artist explores the montage interval in ways distinctive to the aims of the text. JR Carpenter's City Fish appears at first to be a collage of text, image and video, but in reading the story along the horizontal scroll, these fragments cohere into a subjective whole that do not just illustrate the text, but extend meanings in multiple suggestive directions. The work is linear, but the montage reveals a network of associations. Alan Bigelow's playful works similarly layer text, image and video, but in How to Rob A Bank the spatial montage presents familiar interfaces that we can read with ease. The temporal montage of mobile interfaces allows the reader to participate in the thought process of the protagonist through his searches, scheduling and data tracking. Serge Bouchardon's Loss of Grasp extends multimodal montage to gestural interaction, where the user uncovers meanings in the sometimes contradictory or broken relations between text, image, voice and mouse movements. 88 Constellations, by David Clark, is a complex work that uses spatial montage and a constellational navigation map in which the user is compelled to "connect the dots" or fill in the intervals between the enigmatic short narratives. The narratives are relayed in layers of text, graphics, archival moving images, animation and voice. Clark, who has a background in cinema, foregrounds montage aesthetics as both content and interface design. Each constellation-story has within it the "stars" or elements that make up other constellation-stories. The montage recombines certain imagery, making navigation wayward and non-sequential. The whole suggested by these fragments is one that makes the reader aware of the self-referentiality of language and its unreliability as an objective system for mapping the world.

In recombinant or generative works variable and deterministic processes bring elements together in novel ways, but, behind the interface, there is usually careful organization of the fragments and in the programming so that texts, images and sounds combine in somewhat legible and yet surprising arrangements. The big question in composing works that are spaces or processes to explore rather than precise narratives to follow, is how to keep the reader's attention to a developing fiction or idea. In real time video processing, with live juxtapositions of text, audio and video, montage can be said to be a kind of improvisational jamming. VJs of this kind almost certainly have some form of organization of files so that they can be played like notes. In recombinant works of fiction, such as the recombinant cinema works of Rettberg and Coover and my own work and collaborations with Dean and Smith, computation involves a selection of video and sound files that are intended to present a new "shuffling" with each cycle of the work. How do the intervals that come from recombinant montage suggest a virtual whole, a cohesive idea or story? Bill Seaman in reference to his own research/practice in recombinant poetics discusses "fields of meaning" and "conjunction codes" as a way towards a "spatial, environmental understanding of meaning production." The novelty and surprise of the juxtapositions is what makes recombinant works interesting and affective. In the free exploration of machine effects, there is something of Vertovian montage in recombinant works, yet the virtual whole can remain distant and even non-existent. The work holds together by its own perpetual novelty.

"Polyvalent montage" is a term used by some American experimental filmmakers - such as Stan Brakhage, Warren Sonbert and Nathaniel Dosky - to describe a form of editing that is neither dialectical montage (breaking space) nor narrative montage (making space), but rather a subtle network of associations that build in the viewer's growing attention to the unfolding film (Carrol 177-178). Images and sounds resonate more like music than 
linguistic structures. In my recombinant Distant Affinities, I try to incorporate the idea of polyvalent montage to tie together quite disparate images and rhythms of video with short texts from a narrator seeking a unified understanding of the multiplicities. To deliberately break a cohesive space, there are scripted juxtapositions of contrasting temporal rhythms, of subject matter, of camera position and angle. When the user clicks on a particular video or text, the system may pivot, temporarily, into narrative sequences in which human subjects engage in moments of self-reflection within this flux, until the system reverts back into more disjunctive arrangements. The challenge in this kind of open work is in creating a sense that the unity is in the multiplicity; the generative aspect of the work is the virtual whole. The text is a vehicle for getting across ideas and motifs that help with interpretation, but the text must also work as counterpoint to the montage of sound and image. In Distant Affinities, the overall effect is one of dissonance whose intervals suggest a human experience held within a universe of non-human forces.

\section{Rethinking the Interval}

Benjamin and McLuhan tell us that each new communication technology brings with it new ways to conceive and share experience, perhaps even new cosmologies. Bolter and Grusin expand on this idea and add that new communication technologies tend to remediate past forms before establishing new ones. The relatively brief histories of digital art and writing suggest that the possibilities for new forms are enormous, yet in the search for past forms to remediate there is always the problem of narrative. Narrative forms such as novels and movies do not mix well with the new digital techniques that are based on user agency. Montage as a composition practice, however, seems quite natural in a world of cut and paste. And if montage engages the interval as a space for creating virtual wholes, maybe story and fiction are not dependent on narrative sequences alone. A digital fiction is an invented assemblage that conveys both information and affect and need only suggest a whole. Two elder cinema artists, Jean-Luc Godard and Alexander Kluge, have directly addressed the digital usurpation of cinematic montage in ways that open up possible directions for digital fiction and cinematic arts in general.

Godard's late films Goodbye to Language, The Image Book, and particularly Histoire(s) du Cinéma, look more like works of electronic literature than movies. His methods suggest an expanded notion of montage in the world of proliferating images. The works are cranky elegies for a lost golden age of cinema that speak within the ruins of the post-digital. But Godard's dense hieroglyphic style (Godard and Andrew), a handmade, and improvisational form of cinema-writing, is forward-looking and inventive. The works are difficult. They are layered spatial and multi-modal montages that vibrate with potential meanings but are never direct. Color and image effects distort the image, sever illusory space, and bring out the materialities of video. They are amateurish and, in some ways, pre-linguistic gesticulations. What is the "master" of cinema up to? Godard has no developed theory of montage (presumably his films are the theory), but he has repeatedly adopted and reworked the poet Pierre Reverdy's idea of the image as a montage principle:

The image is a pure creation of the mind.

It cannot be born of a comparison, but only of the bringing together of two more or less distant realities.

The more the relations of the two realities brought together are distant and fitting, the stronger the image - the more emotive power and poetic reality it will have...

An image is not strong because it is brutal or fantastic - but because the association of ideas is distant and fitting...

...We create a strong image, one that is new for the mind, by relating, without comparison, two distant realities whose relations can be grasped by the mind alone.... (Reverdy, 50-1) 
This aesthetic of the interval, of poetic association and metaphor, becomes for Godard a technique for making cinema out of images and texts both captured and sampled. It is curious why Godard has not attempted work with the expanded possibilities of digital media. Perhaps his idea of the cinema image is one that only functions in a controlled temporal flow. But his poetics of "distant and fitting" - between images or any semiotic elements - is a useful principle for digital artists and writers who consider the composition processes the key to making new forms of digital fiction.

Alexander Kluge, a prolific German filmmaker and writer, who came out of the New German Cinema movement in the 1960s, was influenced by Godard's montage, but has a more extreme approach to the interval.

In film, a good montage would mean that two pictures which have nothing to do with each other have a gap between them, a contrast, even a contradiction. And there, between the two pictures, there's an epiphany, an invisible picture.

What he calls "constellational filmmaking," where distant images, sounds, stories, scenes, are held together by something like a cosmic force - "a gravitational power, like the sun" - is a montage practice that he also applies to his collections of short stories, his web videos and book collaborations with artists. Sometimes Kluge's images cancel each other out by their contradiction, leaving a void. Great leaps in space, time and genre (from historical documentation to science fiction) leave no chains of associations for the viewer to follow. Instead, Kluge advocates a relaxed and cognitively expansive viewing experience where disparate elements remain in productive flux.

Relaxation means that I myself become alive for a moment, allowing my senses to run wild: for once not to be on guard with the police-like intention of letting nothing escape me. (Langford, 17)

In Kluge's work there are certainly themes and obsessions that tie the historical experience of World War II with speculations about the future of the planet, that contrast love as a revolutionary force with love as force of state control. And connected to his constellational aesthetics is a fascination with smallness, with the personal and anecdotal. Unlike Godard, whose montage is both poetic and destructive, Kluge's montage assembles heterogeneous signs from the universe to create open spaces for contemplation. He does not force connection between things, but rather leaves them in distant relation so that they are held proportionally in mind.

Given that montage is already worked into the creation of many digital texts, how can writers and artists be more conscious of montage in their compositions? Breaking space, relieving the linguistic tendencies to link elements in chains of meaning, can open new ways to conceive of fictional wholes. Digital decomposition and fragmentation might paradoxically lead to more expansive unities in fiction. By adding more space between the elements in their digital fictions, authors can work against the numbing montage effects of social media platforms and algorithmically curated flows that shrink rather than expand the intervals in semiotic life.

\section{Works Cited}

“Alexander Kluge.” The Third Rail, 24 Mar. 2017, http://thirdrailquarterly.org/alexander-kluge/. 
Arsenjuk, Luka. Movement, Action, Image, Montage: Sergei Eisenstein and the Cinema in Crisis. U of Minnesota Press, 2018.

Bigelow, Alan."How to Rob a Bank," https://webyarns.com/howto/howto.html. Accessed 11 Mar. 2020.

Bolter, J. David, and Richard Grusin. Remediation: Understanding New Media. Mit Pr, 1999.

Bouchardon, Serge. "Towards a Tension-Based Definition of Digital Literature". Journal of Creative Writing Studies: Vol. 2 : Iss. 1 , Article 6. 2017, p. 13.

---. Loss of Grasp. https://bouchard.pers.utc.fr/deprise/home. Accessed 11 Mar. 2020.

Carpenter, J. R.. CityFish. http://luckysoap.com/cityfish/. Accessed 11 Mar. 2020.

Carroll, Noel. Theorizing the Moving Image. Cambridge University Press, 1996.

Clark, David. 88 Constellations Preview. http://www.88constellations.net/. Accessed 13 Mar. 2020.

Eisenstein, Sergei. Film Form: Essays in Film Theory. HMH, 2014.

---. The Film Sense. Houghton Mifflin Harcourt, 1947.

Godard, Jean Luc, and Dudley Andrew. Breathless. Rutgers University Press, 1987.

Hayles, N. Katherine. "Literary Texts as Cognitive Assemblages: The Case of Electronic Literature" | Electronic Book Review. http://electronicbookreview.com/essay/literary-texts-as-cognitive-assemblages-the-case-ofelectronic-literature/. Accessed 4 July 2019.

Langford, Michelle. Allegorical Images: Tableau, Time and Gesture in the Cinema of Werner Schroeter. Intellect Books, 2006.

Lialina, Olia. My Boyfriend Came Back from the War. http://www.teleportacia.org/war/. Accessed 11 Mar. 2020.

Luers, Will. "Getting Lost in Narrative Virtuality" | Electronic Book Review.

https://electronicbookreview.com/essay/getting-lost-in-narrative-virtuality/. Accessed 13 Mar. 2020.

---. Hazel Smith and Roger Dean. Novelling. http://novelling.newbinarypress.com/. Accessed 11 Mar. 2020.

---. Distant Affinities. http://will-luers.com/distant-affinities/. Accessed 13 Mar. 2020.

Manovich, Lev, et al. The Language of New Media. MIT Press, 2001.

Miles, Adrian. "Hypertext Structure as the Event of Connection." Journal of Digital Information, vol. 2, no. 3, 2006, https://journals.tdl.org/jodi/index.php/jodi/article/view/48/51. 
Pressman, Jessica. Digital Modernism: Making It New in New Media. 1st edition, Oxford University Press, 2014.

“PRY.” App Store, https://apps.apple.com/us/app/pry/id846195114. Accessed 11 Mar. 2020.

Rettberg, Scott and Roderick Coover. "Toxi•City: A Climate Change Narrative." CRchange, 25 Sept. 2016, https://www.crchange.net/toxicity/.

Seaman, Bill. Recombinant Poetics. http://billseaman.trinity.duke.edu/textsOulipo.php. Accessed 11 Mar. 2020.

The Image | Pierre Reverdy. https://www.sabzian.be/article/the-image. Accessed 5 July 2019.

\section{Cite this Essay}

Luers, Will. "Making and Breaking Space: Rethinking Montage in Digital Writing." Rhizomes: Cultural Studies in Emerging Knowledge, no. 36, 2020, doi:10.20415/rhiz/036.e07 